\title{
Relations among basic psychological needs, PE- motivation and fundamental movement skills in 9-12-year-old boys and girls in Physical Education
}

\author{
I. van Aart, E. Hartman, M. Elferink-Gemser, R. Mombarg \& C. Visscher
}

To cite this article: I. van Aart, E. Hartman, M. Elferink-Gemser, R. Mombarg \& C. Visscher (2015): Relations among basic psychological needs, PE-motivation and fundamental movement skills in 9-12-year-old boys and girls in Physical Education, Physical Education and Sport Pedagogy, DOI: $\underline{10.1080 / 17408989.2015 .1112776}$

To link to this article: http://dx.doi.org/10.1080/17408989.2015.1112776

Published online: 26 Nov 2015.

Submit your article to this journal $\pi$

IIl Article views: 96

View related articles ־

View Crossmark data $\asymp$ 


\title{
Relations among basic psychological needs, PE-motivation and fundamental movement skills in 9-12-year-old boys and girls in Physical Education
}

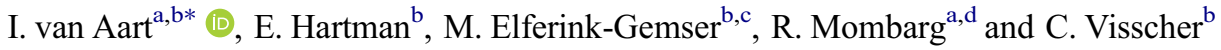 \\ ${ }^{a}$ Institute of Sport Studies, Hanze University of Applied Sciences, Groningen, The Netherlands; \\ ${ }^{b}$ Center for Human Movement Sciences, University Medical Center Groningen, University of \\ Groningen, The Netherlands; ${ }^{c} H A N$ University of Applied Sciences, Arnhem and Nijmegen, The \\ Netherlands; ${ }^{d}$ Faculty of Orthopedagogy, University of Groningen, The Netherlands
}

(Received 24 November 2014; accepted 12 October 2015)

Background: Many children aged 9-12 appear to have low levels of fundamental movement skills (FMS). Physical education (PE) is important because PE-teachers can teach children a variety of FMS and can influence PE-motivation. However, declined levels of PE-motivation are reported in the final grades of elementary school. Therefore, more insight in the relations between PE-motivation and FMS is needed.

Purposes: In the first phase, instruments to measure the satisfaction of basic psychological needs (competence, autonomy, classmate relatedness and teacher relatedness) and PE-motivation (autonomous and controlled) in 9-12-year-old children were developed and validated. The purpose of the second phase was to examine the influence of basic psychological needs on PE-motivation, the influence of PE-motivation on locomotor skills, object control skills and balance skills, and the direct influence of basic psychological needs on FMS for boys and girls aged 9-12. Participants and data collection: In the first phase, 172 children ( 82 boys, 90 girls, $M=$ 10.72 years \pm 0.77 ) filled out questionnaires assessing the satisfaction of their basic psychological needs and motivation for PE. Forty-eight children completed the questionnaires again 4 weeks later. In the second phase, a total of 138 children (66 boys, 72 girls, 10.8 years \pm .79 ) (three schools from phase 1 and one new school) participated. Children from the new school also completed the questionnaires and all children conducted the subtest for speed and agility, upper limb coordination and balance of the Bruininks-Oseretsky Test of Motor Proficiency 2.

Data analysis: In phase 1, linear weighted Kappa's and the Mokken Scale Program for polychotomous items were used to test reliability and validity. In phase 2, Pearson's correlations and multiple linear regression analyses were performed to examine the relations.

Findings: Regarding phase 1, all subscales were reliable and the validity was considered moderate to strong except for the autonomy subscale, which was not reliable and valid. With respect to phase 2, all basic psychological needs, except autonomy among girls, had moderate to strong correlations with autonomous PE-motivation. Teacher relatedness was the most important predictor for boys and girls, while the second predictor was classmate relatedness for boys and competence for girls. No positive significant relations between basic psychological needs and FMS and between PEmotivation and FMS were found. In contrary, moderate but negative relations between teacher relatedness and balance skills and between autonomous PEmotivation and balance skills were found for boys.

*Corresponding author. E-mail: i.van.aart@pl.hanze.nl 
Conclusions: The results confirmed the importance of the basic psychological needs in the prediction of autonomous PE-motivation in 9-12-year-old children. Although all needs should be supported by the PE-teacher, it is important to be aware of the different impact of the needs on autonomous PE-motivation for boys and girls. Despite the missing relations with FMS, PE-teachers seem to be able to autonomously motivate children for PE regardless of their FMS proficiency.

Keywords: physical education; motivation; self-determination; fundamental movement skills; elementary school

\section{Introduction}

Many children aged 9-12 from different countries appear to have low levels of fundamental movement skills (FMS) proficiency (Erwin and Castelli 2008; Goodway, Robinson, and Crowe 2010; Hardy et al. 2012; Spessato et al. 2013). The mastery of FMS, including locomotor skills (i.e. moving the body from one location to another like running and jumping), object control skills (i.e. transportation or interception of objects such as throwing and kicking) and balance skills (i.e. control over the body in stationary and moving positions), is important because FMS are the foundation for more advanced movement sequences (Kalaja et al. 2009) and facilitate successful participation in physical activities (PA) (Stodden et al. 2008; Vandorpe et al. 2012). In an Australian study of 1280 children (11-12 years), $66 \%$ of the boys and $96 \%$ of the girls showed low competence levels in six or all seven tested FMS (four locomotor skills and three object control skills) (Hardy et al. 2012). In an American study of 180 students (9-12 years), many children were indicated as incompetent (i.e. a score below 2 on a 4-point scale) in a basketball task (58\%), a balance task (44\%) and an overhand throwing task (44\%) (Erwin and Castelli 2008). According to the study of Spessato et al. (2013) among 1248 Brazilian children (3-10 years), $69 \%$ of the boys and $82 \%$ of the girls performed below the norms of the Test of Gross Motor Development 2 (Ulrich 2000). Regarding gender differences in FMS proficiency, boys outperformed girls in object control skills, whereas no differences were found in locomotor skills (Goodway, Robinson, and Crowe 2010; Hardy et al. 2012; Lubans et al. 2010; Spessato et al. 2013). Regarding balance skills, Vandorpe et al. (2010) found significantly better test scores for girls, whereas Okely, Booth, and Chey (2004) found no gender differences.

In order to develop a broad range of FMS, children should be offered multiple PA experiences in elementary school years (Hardy et al. 2012). An important setting is Physical Education (PE), whose primary goal is teaching children a wide variety of FMS by offering supportive environments (Kirk 2005) and opportunities to practice (Ericsson, Krampe, and Tesch-Römer 1993). Furthermore, children need to be motivated and engaged in activities in order to develop new skills in school settings (Reeve 2012; Reeve et al. 2004). However, several studies have shown that levels of PE-motivation and enjoyment are declining between grades 4 and 6 (Prochaska et al. 2003; Xiang, McBride, and Guan 2004).

To explore the relation between PE-motivation and FMS Self-Determination Theory (SDT) (Deci and Ryan 1985) can be a valuable framework. According to SDT, two constructs of motivation can be distinguished, namely autonomous motivation (i.e. engaging in activities because of internalized reasons such as fun) and controlled motivation (e.g. engaging in activities because of externalized reasons like receiving rewards) (Haerens et al. 2010). So far, only a small number of studies have examined the relation between PE-motivation and FMS. In these studies among adolescents, weak associations were 
found between autonomous PE-motivation and gymnastic performances $(r=.26)$ (Boiché et al. 2008), balance skills ( $r=.20)$, and locomotor skills $(r=.15)$ (Kalaja et al. 2009).

Furthermore, SDT distinguishes three basic psychological needs; the need for competence (i.e. feelings of effectiveness when trying to master a task), autonomy (i.e. feeling a sense of psychological freedom when carrying out activities) and relatedness (i.e. feeling meaningfully connected to others), which need to be supported in order to initiate or persist in positive behavior during PE (Deci and Ryan 1985; Van den Berghe et al. 2014). Multiple studies in secondary PE have reported moderate to strong associations between perceived competence and autonomous PE-motivation $(r=.32-.66)$, weak to strong associations between autonomy and autonomous PE-motivation $(r=.22-.49)$ and moderate to strong associations between relatedness and autonomous PE-motivation $(r=.37-.60)$ (Cox, Smith, and Williams 2008; Ntoumanis 2005; Standage, Duda, and Ntoumanis 2003, 2005). Furthermore, Cox, Duncheon and McDavid (2009) reported a strong association between feelings of relatedness with the teacher and autonomous PEmotivation $(r=.73)$ and a weak association between feelings of relatedness with classmates and autonomous PE-motivation $(r=.23)$. In conclusion, multiple studies in secondary PE showed moderate to strong relations between basic psychological needs and autonomous PE-motivation (Cox, Smith, and Williams 2008; Ntoumanis 2005; Standage, Duda, and Ntoumanis 2003) and a few studies reported weak relations between autonomous PE-motivation and FMS (Boiché et al. 2008; Kalaja et al. 2009). However, little is known about these relations in elementary school children.

Vallerand, Fortier, and Guay (1997) proposed a motivational sequence in which basic psychological needs influence motivation, and motivation leads to affective (e.g. enjoyment), cognitive (e.g. concentration) and behavioral (e.g. FMS) outcomes, which contribute to children's learning in school (Jang, Reeve, and Deci 2010; Reeve et al. 2004). However, in PE perceived competence might not only indirectly influence FMS proficiency via autonomous PE-motivation as stated by Vallerand's motivational sequence, but also directly. When children grow up they learn to compare more accurately their own performances with those of classmates and as a result the relation between feelings of competence and FMS proficiency becomes stronger (Stodden et al. (2008). Studies of Kalaja et al. (2009) and Barnett et al. $(2008$; 2011) reported weak to moderate direct associations between perceived competence and locomotor skills $(r=.22-.35)$ and between perceived competence and object control skills $(r=.14-.46)$. No previous studies analyzed associations between the need for autonomy and FMS and the need for relatedness and FMS, because these basic needs were assumed to be of less importance in relation to FMS proficiency (Kalaja et al. 2009).

As elementary school is a crucial period for the development of FMS proficiency (Hardy et al. 2012; Stodden et al. 2008), the first aim of this study was to examine Vallerand's motivational sequence (the influence of basic psychological needs on PE-motivation and the influence of PE-motivation on locomotor skills, object control skills and balance skills) and the direct influence of the basic psychological needs on FMS for boys and girls aged 9-12 (Figure 1). PE-teachers can use this information to optimally support basic psychological needs in order to influence levels of PE-motivation and FMS proficiency in children. It was hypothesized that the need for competence would relate both directly and indirectly to the three FMS while the other basic psychological needs were expected to only be indirectly linked (via autonomous PE-motivation) to FMS. The relations are explored separately for boys and girls because of expected gender differences in object control skills and possibly balance skills, which might be partly explained by a difference in PA preference (Spessato et al. 2013). As a result, it was hypothesized that 


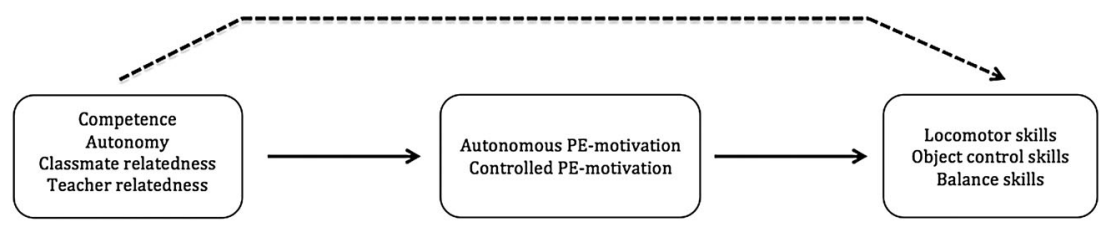

Figure 1. Examined relations between the basic psychological needs, motivation for physical education (PE) and Fundamental Movement Skills. An adapted model based on the Self-Determination Theory (Deci and Ryan 1985).

basic psychological needs and motivation for PE would play a different role in the prediction of FMS proficiency in boys and girls.

The second aim of this paper was the development and validation of the instrumentation of measuring the satisfaction of basic psychological needs and PE-motivation in children aged 9-12. This phase was necessary because the existing instrumentation was only used and validated in adolescent and adult populations in other countries (Aelterman et al. 2012; Vlachopoulos and Michailidou 2006; Wilson et al. 2006). The two aims of this study were addressed within two phases. The first phase describes the development and validation of the measuring instruments and the second phase describes the examination of the direct and indirect relations among basic psychological needs, PE-motivation and FMS.

\section{Method \\ Phase 1 \\ Participants}

Three samples were used in order to validate two questionnaires. The first sample consisted of 12 Dutch children ( 8 girls and 4 boys, $M=9.4$ years \pm 1.2 ) to test the linguistic complexity of the questionnaires in a pilot study. To study the measurement properties of the adapted questionnaires, a second sample of 216 children from grades 4 and 5 of four elementary schools in the city of Groningen, The Netherlands, was invited to participate. Forty-four children were excluded because of lacking permission from parents or missing data points. Therefore, the data of 172 children ( 82 boys and 90 girls, $M=$ 10.72 years \pm 0.77 ) were analyzed. Finally, to perform test-retest analysis, 58 children from one elementary school were invited to fill out the questionnaires a second time. Ten children were excluded because of lacking permission from parents or missing values in the data, resulting in a final sample of 48 children ( 22 boys and 26 girls; $M=10.69$ years \pm 0.72 ). The selection of schools was based on the presence of a PE-specialist and the social economic status (SES) of the neighborhood. One school was located in a high SES neighborhood, two schools in average SES neighborhoods and one school in a low SES neighborhood according to Statistics Netherlands (2011a, 2011b). Written informed consent was obtained from the parents or caregivers prior to data collection. The Ethics Committee of the Center of Movement Sciences from the University Medical Center Groningen, University of Groningen, approved this study.

\section{Measurements}

Basic psychological needs. There are two questionnaires to assess the satisfaction of the needs for competence, autonomy and relatedness in PE, namely the Basic Psychological 
Needs in Exercise Scale (BPNES) (Vlachopoulos and Michailidou 2006) and the Psychological Need Satisfaction in Exercise Scale (PNSES) (Wilson et al. 2006) but both questionnaires are validated in older populations (BPNES: $N=508, M=30.06$ years \pm 8.13 ; PNSES: $N=292, M=20.99$ years \pm 2.96 ). According to De Leeuw, Borgers, and Smits (2004), questionnaires for children aged 7-12 should not contain complex or abstract wording because children tend to interpret words literally. Some items from the PNSES were found to be more complex compared to the BPNES because of the length and formulation of the sentences. Questions were also raised about the generalizability of the autonomy subscale of the PNSES because choice is reflected in many of its items (McDonough and Crocker 2007). Therefore, the BPNES questionnaire was used as a starting point to develop a new questionnaire suitable for children aged 9-12 in a PE-context.

All 12 items of the original BPNES questionnaire were included. Because of expected differences between relations with the teacher and relations with classmates (Cox, Duncheon, and McDavid 2009), the 4 items of the original relatedness subscale were included twice (4 teacher relatedness items and 4 classmate relatedness items) resulting in a total of 16 items. Subsequently, in an attempt to strengthen the current BPNES subscales, additional items from the PNSES, which seemed to complement the BPNES items were included, namely two competence items (e.g. 'I feel like I am capable of doing even the most challenging activities'), three autonomy items (e.g. 'I feel free to choose which activities I participate in') and one relatedness item focusing on the teacher ('I feel attached to my PE-teacher because he/she accepts me as I am'). Finally, 6 PE-teachers were asked to check the questions in the different subscales and to add items they thought were missing in the subscales. Based on discussions with these 6 PE-teachers and literature findings, two new items, one for teacher relatedness ('I feel my PE-teacher gives everyone the same opportunities') (Sarrazin et al. 2006; Skinner and Belmont 1993) and one for classmate relatedness ('I feel attached to my classmates because we accept each other') (Cox, Duncheon, and McDavid 2009) were included. All items follow the stem: 'During the PE class ... .' Responses were provided on a 5-point Likert-scale ranging from 1 (not agree at all) to 5 (very strongly agree). After all additions the new Competence Autonomy classmate-Relatedness and teacher-Relatedness Scale (CARR Scale) consisted of four subscales, that is, competence, autonomy, classmate relatedness and teacher relatedness, including a total of 24 items.

Motivation. An adapted version of the Behavioral Regulations in Physical Education Questionnaire (BRPEQ) of Aelterman et al. (2012) was used to measure autonomous and controlled motivation in PE. Eight items for measuring autonomous motivation and eight items for measuring controlled motivation were included. The original amotivation items were excluded because of the difficulty of the reversed answers for children aged 9-12 (De Leeuw, Borgers, and Smits 2004). The 16 remaining items follow the stem: 'I participate in Physical education because ...' and include items such as '... I think it's important' (autonomous motivation) and ' ... I will feel guilty if I don't' (controlled motivation). Children were asked to report their responses on a 5-point Likert-scale ranging from 1 (not agree at all) to 5 (very strongly agree).

\section{Procedure}

Adaptations in the formulation of the items were needed because of the linguistic complexity for children aged 9-12 and because of language differences between Flemish and Dutch in case of the BRPEQ. First, two researchers and two assistants modified the items followed 
by an evaluation of the intelligibility of the items by two lecturers in primary educational sciences. Finally, linguistic adjustments were made in a pilot study among 12 Dutch children aged 9 and 10 years. Questions that either took more than average time to answer were interpreted in the wrong way or were experienced as difficult were adjusted. The term 'relationship' was therefore changed into 'get along with...,' and some questions were extended with examples: 'The way I exercise is the way I want to, for example I can choose my pace or level.'

In order to measure reliability and validity, 172 children were asked to fill out the questionnaires in the classroom under the supervision of a researcher and two assistants. One of the assistants gave a brief introduction, which has been laid down in a protocol, and used the first question as an example. Children started filling out the questionnaires at their own pace. They were allowed to ask questions after raising their hands. Questions were answered according to a protocol, which indicated standard explanations and examples for every item. On average the measurements took about 30-40 minutes. In order to measure test-retest reliability, the questionnaires were re-administrated in the second sample, using the same protocol at the same time and setting exactly 4 weeks later. The time interval of 4 weeks has been chosen because it was assumed that children would not remember their first responses and minor changes in overall PE-motivation would have occurred.

\section{Data analysis}

First, linear weighted Kappa's were calculated in the subsample of 48 children to analyze test-retest reliability (Terwee et al. 2007). Linear Weighted Kappa's $>.21$ were interpreted as fair (Landis and Koch 1977). Second, the Mokken Scale Program for polychotomous items (MSP, Word version 5.0) was used to identify a set of interrelated items by calculating a scalability coefficient $H$. The $H$ coefficient can be interpreted as weak ( $H$ between .30 and .40 ), moderate ( $H$ between .40 and .50$)$ and strong ( $H$ greater than .50$)$ (Sijtsma, Debets, and Molenaar 1990). Because of the multidimensional data including competence, autonomy, classmate relatedness and teacher relatedness items, a procedure recommended by Meijer and Baneke (2004) was used. In this procedure, a search for scales was initiated increasing the value of $H$ from .05 to .55 in increments of .05 until reliable scales above $H=.30$ were obtained. The internal consistency of each scale is expressed with Rho. Rho $>.70$ indicates a reliable scale (DeJong and Molenaar 1987).

\section{Phase 2}

\section{Participants}

The participants were recruited from four elementary schools, grades 5 and 6 (aged 9-12 years) in the city of Groningen, The Netherlands. The schools were the same as in phase 1, except for the test-retest school, which was replaced by another school. A total of 71 children were excluded because of lacking permission to participate or missing data points. Therefore, data of 138 children ( 66 boys and 72 girls, $M=10.8$ years \pm 0.79 ) are included in this study. All participating schools offer two hours of PE per week taught by a specialized PE-teacher in coeducational PE-classes. Similar as in phase 1, active written informed consent was obtained from the parents or caregivers prior to data collection. The Ethics Committee of the Center of Movement Sciences from the University Medical Center Groningen, University of Groningen, approved this study. 


\section{Measurements}

Basic psychological needs and motivation. The new CARR Scale was used to measure the satisfaction of the basic psychological needs and the adapted BRPEQ (Aelterman et al. 2012) was used to measure autonomous and controlled motivation. Measurement properties of both questionnaires were tested before the use in phase 2 and are presented in the result section of phase 1. For an overview of the items, see Appendices 1 and 2.

Fundamental movement skills. Three subtests of the Bruininks-Oseretsky Test of Motor Proficiency 2 (BOT-2) (Bruininks and Bruininks 2005) were used. The psychometric qualities of the BOT-2 test are sufficient with a test-retest reliability of .85 and an inter-rater reliability for all subtests above .98 (Bruininks and Bruininks 2005). Furthermore, three validity studies showed strong support for adequate construct validity of the BOT-2 (Deitz, Kartin, and Kopp 2007). Locomotor skills (e.g. running and hopping) were assessed with the speed and agility test, object control skills (e.g. throwing and catching) were measured with the upper limb coordination test and balance skills were assessed with the balance skill test. For an overview of the measured items in the three subtests, see Appendix 3. Raw scores on each test-item were converted into point scores and all point scores per subtest were added to calculate a total point score (range point scores: locomotor skills: $0-52$, object control skills: $0-39$, balance skills: $0-37)$. The body mass index (BMI) of each child was calculated (weight/(height)2, because of possible relations between FMS and BMI (Okely, Booth, and Chey 2004).

\section{Procedure}

The procedure regarding the questionnaires has been described in phase 1. After filling out the questionnaires, levels of FMS proficiency were assessed at multiple test stations in the gymnasium during two PE-classes. At every station a trained examiner administered testitems of a specific subtest in groups of not more than five children, who were asked to move along all the stations. The period between the completion of the questionnaire and execution of the movement tests ranged between 4 weeks and 12 weeks. However, three of the four schools were tested within 10 weeks.

\section{Data analysis}

Statistical analyses were conducted using SPSS for Windows, version 22.0 and the significance level was set at .05. First, descriptive statistics were calculated for all basic psychological needs, PE-motivation and FMS variables. Second, independent $t$-tests were performed on all variables (i.e. competence, autonomy, classmate relatedness, teacher relatedness, autonomous motivation, controlled motivation, locomotor skills, object control skills and balance skills) to compare mean values between boys and girls. Third, Pearson's correlations were conducted to examine relations among all variables. Also, Pearson correlations with BMI were calculated, because of possible relations with BMI (Okely, Booth, and Chey 2004). Correlations of $r=.10$ were interpreted as weak, $r=.30$ as moderate and $r=.50$ as strong associations (Field 2009). Fourth, multiple linear regression analyses were performed on variables with significant correlations (McDonald 2014). Primarily, the influences of basic psychological needs (i.e. independent variables) on PE-motivation (i.e. dependent variables) were analyzed. The basic psychological needs were simultaneously included in the regression model because SDT assumes that all basic psychological 
needs co-exist (Edmunds, Ntoumanis, and Duda 2006). Second, the influence of PE-motivation (i.e. independent variables) on FMS (i.e. dependent variables) was calculated. Finally, the direct influence of the basic psychological needs (i.e. independent variables) on FMS (i.e. dependent variables) was identified. When FMS were significantly correlated with BMI, the regression analyses were checked for BMI. Fifth, to test whether autonomous and controlled motivation for PE mediate the relation between the basic psychological needs and FMS, the following criteria were taken into account: (1) the predictor variables (basic psychological needs) are significantly associated with the outcome variables (FMS); (2) the predictor variables are significantly associated with the mediating variables (PEmotivation); (3) the mediating variables are associated with the outcome variables and (4) the addition of the mediator variables in the total model reduces the relation between the predictor variables and the outcome variables to a non-significant value (Baron and Kenny 1986). To test the significance of the mediation effect, the Sobel test recommended by Baron and Kenny was performed. The Sobel test is significant if the strength of the association between the predictor variable and the outcome variable is significantly smaller when the mediating variable is included, indicating an indirect pathway. Because the direction of the associations was expected to be positive, mediation analysis was only performed when positive significant associations had been found.

\section{Results \\ Phase 1}

\section{Basic psychological needs (CARR Scale)}

Linear Weighted Kappa's for all 24 items of the CARR Scale ranged between .21 and .60 and therefore no items were excluded. Furthermore, Mokken Scale analysis resulted in five subscales. Regarding competence, two items were excluded (e.g. 'I feel I made a lot of progress in relation to the goal I wanted to achieve this year'), remaining four items in the competence scale with a scalability $H$ of .55 and Rho $=.81$. Concerning autonomy, three items were excluded including 'the way I exercise is the way I want to.' This resulted in two autonomy subscales containing only two items per scale with scalabilities $H$ of .47 and .46 and internal consistencies of, respectively, .61 and .63. Analysis of the four autonomy items together showed a scalability $H$ of .38 and Rho $=.67$. Regarding, classmate relatedness, the item 'I feel attached to my classmates because we are looking after each other' was excluded. The remaining classmate relatedness subscale consisted of four items with a scalability $H$ of .58 and Rho $=.82$. The fifth scale, teacher relatedness, contained six items (no items were excluded) with a scalability $H$ of .64 and an internal consistency of Rho $=.89$. Therefore, the final CARR Scale consisted of four subscales, that is, competence, autonomy, classmate relatedness and teacher relatedness, and contained a total of 18 items (Appendix 1). All subscales were valid (scalability $\geq .40$ ) and reliable (Rho $\geq .70$ ) except for the autonomy subscale (scalability .38 and Rho .67).

\section{Motivation (adapted BRPEQ)}

Linear Weighted Kappa's ranged between .08 and .59 for autonomous motivation and between .15 and .69 for controlled motivation. Therefore, two items were deleted including 'because I otherwise get criticized by my classmates' (controlled) and 'because this PEclass is personally important to me' (autonomous). Mokken Scale Analysis resulted in two subscales. The first subscale, autonomous motivation, consisted of seven items, with 
a scalability $H$ of .51 and internal consistency of Rho $=.87$. The second subscale, controlled motivation, consisted of five items (two items were excluded 'because I feel guilty if I don't' and 'because I have to prove myself to others') with a scalability $H$ of .42 and Rho $=.72$. Finally, the adapted BRPEQ consisted of 12 items with valid and reliable subscales for autonomous PE-motivation and controlled PE-motivation. (For an overview of the items see Appendix 2.)

\section{Phase 2}

\section{Descriptive statistics}

Descriptive statistics for all variables are presented in Table 1. On average, children experienced a good relationship with their classmates, a positive relationship with their teacher and felt somewhat competent in successfully performing different PE tasks. However, they did not perceive a lot of autonomy during PE-lessons. Furthermore, children were autonomously motivated for PE and scored well above the mathematical midpoint on locomotor skills, object control skills and balance skills. The $t$-tests revealed that boys scored significantly higher on perceived competence where girls scored significantly higher on balance skills. No gender differences were found for object control skills and locomotor skills.

\section{Correlations among basic psychological needs, PE-motivation and FMS proficiency}

In Table 2(A and B), the results of Pearson's correlations for boys and girls are presented. Moderate to strong correlations $(r=.30-.64)$ were found between all basic psychological needs and autonomous PE-motivation for both boys and girls, except for a weak correlation with autonomy for girls $(r=.25)$. No significant correlations were found between basic psychological needs and controlled PE-motivation, between PE-motivation and locomotor skills, between PE-motivation and object control skills and between basic psychological needs and FMS for both boys and girls. However, a weak correlation between the need for autonomy and object control skills was found for girls $(r=.25)$.

Table 1. Descriptive statistics and internal consistencies of all subscales.

\begin{tabular}{|c|c|c|c|c|c|}
\hline & Range & $\begin{array}{c}\text { Mean (SD) } \\
\text { Boys } \\
(\mathrm{n}=66)\end{array}$ & $\begin{array}{c}\text { Mean (SD) } \\
\text { Girls } \\
(\mathrm{n}=72)\end{array}$ & $t$-test $(p)$ & Internal consistency \\
\hline \multicolumn{6}{|l|}{ Basic psychological needs } \\
\hline Competence & $1.8-5.0$ & $3.77(.72)$ & $3.42(.69)$ & .00 & .81 \\
\hline Autonomy & $1.0-4.3$ & $2.33(.67)$ & $2.47(.67)$ & 20 & .67 \\
\hline Classmate relatedness & $2.0-5.0$ & $4.08(.64)$ & $4.00(.63)$ & .29 & .82 \\
\hline \multirow{2}{*}{\multicolumn{6}{|c|}{ Motivation for PE }} \\
\hline & & & & & \\
\hline Autonomous motivation & $1.7-5.0$ & $3.75(.71)$ & $3.68(.71)$ & .61 & .87 \\
\hline $\begin{array}{l}\text { Controlled motivation } \\
F M S\end{array}$ & $1.0-3.2$ & $1.30(.41)$ & $1.41(.51)$ & .15 & .72 \\
\hline Locomotor skills & $31-48$ & $40.82(3.80)$ & $41.24(3.22)$ & .48 & .79 \\
\hline Object control skills & $26-39$ & $35.73(2.38)$ & $34.92(2.73)$ & .07 & .82 \\
\hline Balance skills & $24-37$ & $33.00(2.57)$ & $34.18(2.09)$ & .00 & .80 \\
\hline
\end{tabular}


Table 2. Correlation coefficients between all basic psychological needs, motivation for PE and FMS, (A) boys $(n=66)$ and $(B)$ girls $(n=72)$.

\begin{tabular}{|c|c|c|c|c|c|c|c|c|c|c|}
\hline & 1 & 2 & 3 & 4 & 5 & 6 & 7 & 8 & 9 & 10 \\
\hline \multicolumn{11}{|l|}{ (A-boys) } \\
\hline Competence & 1 & & & & & & & & & \\
\hline Autonomy & -.02 & 1 & & & & & & & & \\
\hline Classmate relatedness & $.40^{* *}$ & .08 & 1 & & & & & & & \\
\hline Teacher relatedness & .24 & $.46^{* *}$ & $.30^{*}$ & 1 & & & & & & \\
\hline Autonomous PE-motivation & $.39^{* *}$ & $.30^{*}$ & $.45^{* *}$ & $.64^{* *}$ & 1 & & & & & \\
\hline Controlled PE-motivation & -.12 & .24 & -.20 & .14 & .22 & 1 & & & & \\
\hline Locomotor skills & .23 & -.06 & -.05 & -.12 & .01 & -.15 & 1 & & & \\
\hline Object control skills & .19 & -.09 & .18 & -.07 & .11 & -.04 & $.34^{* *}$ & 1 & & \\
\hline Balance skills & -.23 & -.04 & -.13 & $-.35^{* *}$ & $-.36^{* *}$ & -.15 & .20 & .22 & 1 & \\
\hline \multirow{2}{*}{\multicolumn{11}{|c|}{ (B-girls) }} \\
\hline & & & & & & & & & & \\
\hline Competence & 1 & & & & & & & & & \\
\hline Autonomy & .15 & 1 & & & & & & & & \\
\hline Classmate relatedness & $.44^{* *}$ & -.00 & 1 & & & & & & & \\
\hline Teacher relatedness & $.42^{* *}$ & $.42^{* *}$ & $.31^{* *}$ & 1 & & & & & & \\
\hline Autonomous PE-motivation & $.54^{* *}$ & $.25^{*}$ & $.30^{*}$ & $.56^{* *}$ & 1 & & & & & \\
\hline Controlled PE-motivation & -.07 & .16 & -.14 & -.14 & -.01 & 1 & & & & \\
\hline Locomotor skills & .14 & .06 & .06 & .10 & .14 & -.18 & 1 & & & \\
\hline Object control skills & -.02 & $.25^{*}$ & .04 & .15 & -.05 & -.04 & $.54^{* *}$ & 1 & & \\
\hline Balance skills & -.11 & -.08 & .06 & -.15 & -.11 & -.06 & .16 & .00 & 1 & \\
\hline BMI & .19 & .16 & .16 & .15 & .14 & .13 & -.20 & -.03 & .00 & 1 \\
\hline
\end{tabular}

${ }^{*} p<.05$.

${ }^{* *} p<.01$. 
Table 3. Regression analysis predicting autonomous motivation for PE from the basic psychological needs in $(\mathrm{A})$ boys $(\mathrm{n}=66)$ and $(\mathrm{B})(\mathrm{n}=72)$.

\begin{tabular}{|c|c|c|c|c|c|}
\hline & $B$ & Beta & $t$ & $p$ & $95 \% \mathrm{CI}$ for $\mathrm{B}$ \\
\hline \multicolumn{6}{|l|}{ (A) } \\
\hline Constant & .33 & & .67 & .51 & -.66 to 1.33 \\
\hline Competence & .18 & .18 & 1.84 & .07 & -.02 to .38 \\
\hline Autonomy & .06 & .06 & .55 & .59 & -.16 to .27 \\
\hline Classmate relatedness & .25 & .22 & 2.21 & .03 & .02 to .47 \\
\hline $\begin{array}{l}\text { Teacher relatedness } \\
\text { (B) }\end{array}$ & .45 & .51 & 4.75 & .00 & .26 to .65 \\
\hline Constant & .99 & & 2.00 & .05 & .05 to 1.98 \\
\hline Competence & .37 & .36 & 3.34 & .00 & .15 to .59 \\
\hline Autonomy & .04 & .03 & .32 & .75 & -.18 to .25 \\
\hline Classmate relatedness & .02 & .02 & .15 & .89 & -.22 to .25 \\
\hline Teacher relatedness & .37 & .39 & 3.45 & .00 & .16 to .58 \\
\hline
\end{tabular}

\section{Relationships between basic psychological needs and PE-motivation}

Multiple linear regression analysis showed that the needs for teacher relatedness and classmate relatedness were positive significant predictors of autonomous PE-motivation for boys (teacher relatedness: $B=.45, p=.00$; classmate relatedness: $B=.25, p=$ .03) (Table 3(A)). The model including all basic psychological needs explained $51.2 \%$ of the variance of autonomous PE-motivation for boys. The analysis for girls showed that both the need for teacher relatedness and the need for competence were significant predictors of autonomous PE-motivation (teacher relatedness: $B=.37, p=.00$; competence: $B=.37, p=.00$ ) (Table 3(B)). The model including all basic psychological needs explained $43.0 \%$ of the variance of autonomous PE-motivation for girls. No significant correlations between basic psychological needs and controlled PE-motivation were found for boys and girls. Therefore, no regression analyses of these variables were performed.

\section{Relationships between PE-motivation and FMS proficiency}

The only significant correlation between autonomous PE-motivation and each of the three FMS was the correlation between autonomous PE-motivation and balance skills for boys. No significant correlations were found between controlled PE-motivation and the three FMS. Therefore, regression analysis was only performed with these variables. The analysis showed that autonomous PE-motivation was a negative significant predictor of balance skills for boys $(B=-1.30, p=.00)$ and explained $12.9 \%$ of the variance in balance skills (Table 4).

Table 4. Regression analysis predicting balance skills from autonomous PE motivation in boys.

\begin{tabular}{lrrrrr}
\hline & $B$ & Beta & $t$ & $p$ & $95 \%$ CI for B \\
\hline Balance skills & & & & & \\
Constant & 37.85 & & 23.56 & .00 & 34.64 to 41.06 \\
Autonomous PE-motivation & -1.30 & -.36 & -3.08 & .00 & -2.14 to -.45 \\
\hline
\end{tabular}


Table 5. Regression analysis predicting object control skills and balance skills from the basic psychological needs in boys $(\mathrm{n}=66)$.

\begin{tabular}{lrrrrr}
\hline \multicolumn{1}{c}{$B$} & Beta & \multicolumn{1}{c}{$t$} & $p$ & 95\% CI for B \\
\hline Balance skills & & & & & \\
Constant & 37.72 & & 16.03 & .00 & 33.02 to 42.43 \\
Competence & -.54 & -.15 & -1.17 & .25 & -1.47 to .38 \\
Autonomy & .50 & .13 & .98 & .233 & -.52 to 1.52 \\
Classmate relatedness & .13 & .03 & .25 & .81 & -.92 to 1.19 \\
Teacher relatedness & -1.25 & -.39 & -2.76 & .01 & -2.15 to -.34 \\
\hline
\end{tabular}

Table 6. Regression analysis predicting object control skills from the basic psychological needs in girls.

\begin{tabular}{lrrrrr}
\hline & $B$ & Beta & $t$ & $p$ & $95 \%$ CI for B \\
\hline Object control skills & & & & & \\
Constant & 32.02 & & 13.11 & .00 & 27.15 to 36.90 \\
Competence & -.46 & -.12 & -.84 & .40 & -1.56 to .63 \\
Autonomy & .95 & .24 & 1.80 & .08 & -.10 to 2.01 \\
Classmate relatedness & .27 & .06 & .46 & .65 & -.89 to 1.43 \\
Teacher relatedness & .31 & .09 & .59 & .56 & -.74 to 1.35 \\
\hline
\end{tabular}

Relationships between basic psychological needs and FMS proficiency

For boys, only the need for teacher relatedness was significantly but negatively correlated with balance skills. No other correlations between basic psychological needs and any of the three FMS were found. The multiple linear regression analysis indicated that the need for teacher relatedness was a negative significant predictor of balance skills $(B=$ $-1.25, p=.01$ ), which explained $12.5 \%$ of the variance. The total model including all basic psychological needs explained $16.2 \%$ of the variance in balance skills (Table 5).

For girls, the need for autonomy was significantly positively correlated with object control skills. No other correlations were found between basic psychological needs and proficiency in the three FMS. The regression analysis showed that the need for autonomy was not a significant predictor of object control skills after including all basic psychological needs in the model $(B=.95, p=.08)$. This model explained $8 \%$ of the variance of object control skills in girls (Table 6).

Because of missing relations with FMS proficiency, none of the variables met the criteria for mediation. Therefore, no mediation analyses were performed.

\section{Discussion}

\section{Phase 1}

The second aim of this study was to validate the CARR Scale and the adapted BRPEQ for children aged 9-12 years. With regard to the CARR Scale, the subscales for competence, classmate relatedness and teacher relatedness are considered strong scales. However, the combined subscale for autonomy turned out to be a weak scale with a scalability $H$ of .38 and Rho of .67. According to the study of McDonough and Crocker (2007), many choice-related items in the questionnaire can result in measurement issues if the respondents participate in a context with a clear leader such as the PE-teacher. The PE-teacher makes 
already a lot of conditional decisions often based on the nature of the activities offered, thereby limiting the feeling of autonomy in children. During the development of the CARR Scale items such as 'the way I exercise is the way I want to' were included. However, because of low reliability and validity of these items the final combined subscale only contained choice-related items. These items can result in limited variance because children might interpret the autonomy items too literally (De Leeuw, Borgers, and Smits 2004). Based on this validation study, it is recommended to examine autonomy in the actual context by observations or to develop and use a context-specific autonomy subscale in future studies. However, to get a general idea of the construct and its relations with the other variables in this study, the subscale was applied in the second phase. Though, the results in the next phase were interpreted with caution.

Regarding the measurement of motivation in PE, this study shows that the autonomous motivation subscale is a strong and reliable scale and the controlled motivation subscale is a moderate and reliable scale for children aged 9-12.

\section{Phase 2}

The first aim of the study was to examine the influence of basic psychological needs on motivation and the influence of motivation on locomotor skills, object control skills and balance skills (Vallerand's motivational sequence) and the direct influence of the basic psychological needs on FMS for boys and girls aged 9-12.

\section{Relationships between basic psychological needs and PE-motivation}

The finding that basic psychological needs were moderately to strongly associated with autonomous PE-motivation, except the need of autonomy for girls, is in line with previous SDT research (Cox, Smith, and Williams 2008; Ntoumanis 2005; Standage, Duda, and Ntoumanis 2005) and confirms this part of the theory for 9-12-year-old children. The exception for the autonomy subscale could be explained by biased results due to the use of the weak subscale. In this study, the strongest relation was found between teacher relatedness and autonomous PE-motivation for both boys and girls. Previous studies in PE often examined the need for competence and found strong associations with autonomous PEmotivation (Kalaja et al. 2009; Ntoumanis 2005). However, a few other studies also found the highest correlations between the need for relatedness and autonomous motivation in PE settings (Cox, Duncheon, and McDavid 2009; Cox, Smith, and Williams 2008; Standage, Duda, and Ntoumanis 2003). The finding that perceived competence is a significant predictor of autonomous PE-motivation for girls might result from the fact that their perceived competence levels were lower which possibly results in a stronger need for competence. Previous studies also reported lower perceived competence levels in PE for girls compared to boys (Lyu and Gill 2011; Slingerland et al. 2014). The finding that classmate relatedness is a significant predictor of autonomous PE-motivation for boys is possibly related to their preferences for team sports (Rose and Rudolph 2006). Children have to work together as a team and good relations between classmates can be important for the motivation to play games.

\section{Relationships between PE-motivation and FMS proficiency}

No significant positive relations between autonomous PE-motivation and FMS proficiency were found in this study. Children scored well above the mathematical midpoint on 
autonomous PE-motivation regardless of their level of FMS proficiency. It is possible that children did not take the level of their FMS proficiency into account while filling out the motivation questionnaire. An explanation could be found in the assessment of overall motivation for PE in this study instead of the motivation for specific FMS. This might also be influenced by the fact that Dutch PE-teachers are more focused on fun than on FMS development in PE (Van Weerden, Van der Schoot, and Hemker 2008). Therefore, it is possible that children do not link their motivation for PE to their FMS proficiency but link their motivation for PE to their basic psychological needs. Nevertheless, most children scored their level of autonomous PE-motivation well above the mathematical midpoint with teacher relatedness as an important influence. This finding suggests that PE-teachers are able to support autonomous PE-motivation of most of the children irrespective of their FMS proficiency. Another possibility for the missing relations between PE-motivation and FMS is the assessment of FMS by the BOT-2. Although Cools et al. (2009) refer to it as an FMS test, the BOT-2 does not claim to measure the domains 'locomotor' and 'object control' skills. Therefore, it is possible that these domains were not fully measured. Besides, the BOT-2 is a product measure (i.e. focusing on the outcome such as the number of successful attempts), while a process measure (i.e. focusing on the proficiency of the performance) (Morgan et al. 2005) might have resulted in different conclusions. In future research, it is important to take both process and product measures for FMS into account.

Contrary to expectations, a negative relation between autonomous PE-motivation and balance skills was found for boys. Kalaja et al. (2009) reported that in terms of coordination, static balance skills could be considered as less complex compared to locomotor and object control skills. According to Scully and Clarke (1997), boys have a preference for complex sport tasks. The motivated boys might have felt less challenged, bored or impatient to perform the balance tasks in this study, which could have influenced their test scores negatively. This result implies that autonomous motivation for PE is not always related to higher levels of FMS proficiency.

\section{Relationships between basic psychological needs and FMS proficiency}

Regarding the relationships between basic psychological needs and FMS proficiency, no significant relations were found between perceived competence and FMS proficiency for boys and girls. This is in contrast with previous studies, which reported a positive correlation between perceived competence and FMS tests (Barnett et al. 2008, 2011; Kalaja et al. 2009). During children's development, they become more capable of accurately comparing their FMS proficiency with classmates, which results in stronger correlations between perceived competence and FMS proficiency (Stodden et al. 2008). The missing relation in the current study might be explained by the Dutch Physical Education system. PE-teachers in the Netherlands can develop their own PE-curricula and although FMS mastery is stated to be one of two core objectives in Dutch elementary PE (Stichting Leerplanontwikkeling 2006). Dutch PE-teachers consider positive and fun experiences in sport even more important (Van Weerden, Van der Schoot, and Hemker 2008). It is possible that because of the focus on fun in PE, teachers do not confront children with their actual FMS proficiency. In addition, FMS skills are not assessed in most of the Dutch elementary schools. Therefore, children are not supported in acquiring a realistic view of their FMS proficiency. Despite different FMS levels, most of the children in the current study feel somewhat competent in performing PE-activities. Again, the lack of relationship between perceived competence and FMS could be a consequence of using the BOT-2. It 
is possible that children relate their feelings of competence to the process (e.g. technique) rather than the product (e.g. successful scoring). Therefore, a more process-oriented measure for FMS might have resulted in different findings.

As expected, none of the other basic psychological needs were predictors of FMS proficiency, except for teacher relatedness, which negatively predicted balance skills for boys. A significant but weak relation was found between the need for autonomy and object skills for girls; however, these results could not be interpreted properly due to the use of the weak subscale. In previous studies, these basic psychological needs were only examined in direct relation with motivation (Cox, Smith, and Williams 2008; Ntoumanis 2005; Standage, Duda, and Ntoumanis 2005) and not linked to FMS proficiency. This study confirms the absence of a positive link. Because of the lack of relations with FMS proficiency, no mediation analyses were performed.

\section{Strengths and limitations}

Strengths of this study include the application of the SDT framework for 9-12-year-old boys and girls, a younger population compared to previous research in the context of PE. In this study, existing measuring instruments were adapted to make it possible to further examine and monitor motivational processes in this younger age group. Another strength of this study is the analysis of the need for relatedness separately for the teacher and classmates, which gives more details about the motivational process. This study confirms the previous findings of Cox, Duncheon and McDavid (2009) in which the relationship with the PE-teacher is more important for autonomous PE-motivation than the relationship with other classmates in this age group.

However, some limitations of this study need to be considered as well. A first limitation of this study is the marginal internal consistency of the autonomy subscale. Therefore, it is possible that not the whole concept of autonomy was measured. Improvements in the assessment of autonomy, which might entail other methods like observations, should be investigated further. Second, results of this study indicate that the assessment of motivation for PE might be too general to find relations between motivation and FMS proficiency for 9-12-year-old children. Third, as mentioned in the discussion, the BOT-2 might not capture the entire concepts of object control skills and locomotor skills. The use of both process and product measures of FMS in future research is recommended. Finally, the time interval between the administration of the questionnaires and the execution of the BOT-2 was at most three months and might have resulted into changes in FMS scores. However, based on the norm references of the BOT-2 test (Bruininks and Bruininks 2005), which are divided into half-year periods, the impact of these changes is assumed to be minor especially because no specific FMS training was provided within this time interval.

\section{Conclusion}

The present study extends the body of research of SDT in relation to FMS in the field of elementary PE. The study confirms the importance of the satisfaction of basic psychological needs in the prediction of autonomous PE-motivation for 9-12-year-old boys and girls, especially the relation with the teacher. However, the need for classmate relatedness seems to be an important predictor of autonomous PE-motivation for boys while for girls the need for competence has more influence. Although all needs should be supported by the PE-teacher, it is important for teachers to be aware of the different impact of the 
needs on autonomous PE-motivation for boys and girls. With this information, the teacher has an opportunity to better align its strategies to the specific needs of boys and girls. Furthermore, no positive significant relations between basic psychological needs and levels of FMS proficiency and between PE-motivation and levels of FMS were found. It seems that Dutch children link their autonomous motivation for PE with the satisfaction of their basic psychological needs and not with their levels of FMS proficiency. A positive aspect of the lacking relationships with FMS is that PE-teachers seem to be able to autonomously motivate children for PE regardless of the proficiency of adequate FMS levels. Further research should examine the link between basic psychological needs, motivation for specific sport skills and FMS.

\section{Acknowledgements}

We thank the students, teachers and schools for participating in this study. Furthermore, we thank the students and teachers from the Institute of Sport Studies and the students Maaike Walgemoed and Maaike Jongman-Grob from the Center of Human Movement Sciences for their assistance in conducting the study.

\section{ORCID}

I. van Aart (D) http://orcid.org/0000-0003-0845-3306

\section{References}

Aelterman, N., M. Vansteenkiste, H. Van Keer, L. Van den Berghe, J. De Meyer, and L. Haerens. 2012. "Students' Objectively Measured Physical Activity Levels and Engagement as a Function of between-Class and between-Student Differences in Motivation Toward Physical Education.” Journal of Sport and Exercise Psychology 34 (4): 457-480.

Barnett, L. M., P. J. Morgan, E. Van Beurden, K. Ball, and D. R. Lubans. 2011. "A Reverse Pathway? Actual and Perceived Skill Proficiency and Physical Activity." Medicine \& Sciences in Sports \& Exercise 43 (5): 898-904.

Barnett, L. M., P. J. Morgan, E. Van Beurden, and J. R. Beard. 2008. "Perceived Sports Competence Mediates the Relationship between Childhood Motor Skill Proficiency and Adolescent Physical Activity and Fitness: A Longitudinal Assessment." International Journal of Behavioral Nutrition and Physical Activity 5 (1): 40-52.

Baron, R. M., and D. A. Kenny. 1986. "The Moderator-mediator Variable Distinction in Social Psychological Research: Conceptual, Strategic, and Statistical Considerations." Journal of Personality and Social Psychology 51 (6): 1173-1182.

Boiché, J. C. S., P. G. Sarrazin, F. M. E. Grouzet, L. G. Pelletier, and J. P. Chanal. 2008. "Students' Motivational Profiles and Achievement Outcomes in Physical Education: A Self-Determination Perspective." Journal of Educational Psychology 100 (3): 688-701.

Bruininks, R. H., and B. D. Bruininks. 2005. BOT-2; Bruininks-Oseretsky Test of Motor Proficiency. 2nd ed. Minneapolis, MN: Pearson.

Cools, W., K. De Martelear, C. Samaey, and C. Andries. 2009. "Movement Skill Assessment of Typically Developing Preschool Children: A Review of Seven Movement Skill Assessment Tools." Journal of Sport Science \& Medicine 8 (2): 154-168.

Cox, A. E., N. Duncheon, and L. McDavid. 2009. "Peers and Teachers as Sources of Relatedness Perceptions, Motivation, and Affective Responses in Physical Education." Research Quarterly for Exercise and Sport 80 (4): 765-773.

Cox, A. E., A. Smith, and L. Williams. 2008. "Change in Physical Education Motivation and Physical Activity Behavior during Middle School.” Journal of Adolescent Health 43 (5): 506-513.

Deci, E. L., and R. M. Ryan. 1985. Intrinsic Motivation and Self-Determination in Human Behavior. New York: Plenum Press. 
Deitz, J. C., D. Kartin, and K. Kopp. 2007. "Review of the Bruininks-Oseretsky Test of Motor Proficiency, (BOT-2)." Physical \& Occupational Therapy in Pediatrics 27 (4): 87-102.

DeJong, A., and I. W. Molenaar. 1987. "An Application of Mokken's Model for Stochastic, Cumulative Scaling in Psychiatric Research.” Journal of Psychiatric Research 21 (2): 137-149.

De Leeuw, E., N. Borgers, and A. Smits. 2004. "Pretesting Questionnaires for Children and Adolescents." In Methods for Testing and Evaluating Survey Questionnaires, edited by S. Presser, J. M. Rothgeb, M. P. Couper, J. T. Lessler, E. Martin, J. Martin, and E. Singer, 409429. Hoboken, NJ: John Wileys \& Sons.

Edmunds, J., N. Ntoumanis, and J. L. Duda. 2006. "A Test of Self-determination Theory in the Exercise Domain." Journal of Applied Social Psychology 36 (9): 2240-2265.

Ericsson, K. A., R. T. Krampe, and C. Tesch-Römer. 1993. "The Role of Deliberate Practice in the Acquisition of Expert Performance." Psychological Review 100 (3): 363-406.

Erwin, H. E., and D. M. Castelli. 2008. "National Physical Education Standards: A Summary of Student Performance and its Correlates." Research Quarterly for Exercise and Sport 79 (4): 495-505.

Field, A. 2009. Discovering Statistics using SPSS. Los Angeles: Sage Publications.

Goodway, J. D., L. E. Robinson, and H. Crowe. 2010. "Gender Differences in Fundamental Motor Skill Development in Disadvantaged Preschoolers from Two Geographical Regions." Research Quarterly for Exercise and Sport 81 (1): 17-24.

Haerens, L., D. Kirk, G. Cardon, I. De Bourdeaudhuij, and M. Vansteenkiste. 2010. "Motivational Profiles for Secondary School Physical Education and its Relationship to the Adoption of a Physically Active Lifestyle among University Students." European Physical Education Review 16 (2): $117-139$.

Hardy, L. L., T. Reinten-Reynolds, P. Espinel, A. Zask, and A. D. Okely. 2012. "Prevalence and Correlates of Low Fundamental Movement Skill Competency in Children.” Pediatrics 130 (2): e390-e398.

Jang, H., J. Reeve, and E. L. Deci. 2010. "Engaging Students in Learning Activities: It is Not Autonomy Support Or Structure but Autonomy Support and Structure." Journal of Educational Psychology 102 (3): 588-600.

Kalaja, S., T. Jaakkola, A. Watt, J. Liukkonen, and Y. Ommundsen. 2009. "The Associations between Seventh Grade Finnish Students' Motivational Climate, Perceived Competence, Self-Determined Motivation, and Fundamental Movement Skills." European Physical Education Review 15 (3): $315-335$.

Kirk, D. 2005. "Physical Education, Youth Sport and Lifelong Participation: The Importance of Early Learning Experiences." European Physical Education Review 11 (3): 239-255.

Landis, J. R., and G. G. Koch. 1977. "The Measurement of Observer Agreement for Categorical Data." Biometrics 33 (1): 159-174.

Lubans, D. R., P. J. Morgan, D. P. Cliff, L. M. Barnett, and A. D. Okely. 2010. "Fundamental Movement Skills in Children and Adolescents." Sports Medicine 40 (12): 1019-1035.

Lyu, M., and D. L. Gill. 2011. "Perceived Physical Competence, Enjoyment and Effort in Same-sex and Coeducational Physical Education Classes." Educational Psychology 31 (2): 247-260.

McDonald, J. H. ed. 2014. Handbook of Biological Statistics. 3rd ed. Baltimore, MD: Sparky House Publishing.

McDonough, M., and P. R. E. Crocker. 2007. "Testing Self-Determined Motivation as a Mediator of the Relationship between Psychological Needs and Affective and Behavioral Outcomes." Journal of Sport and Exercise Psychology 29 (5): 645.

Meijer, R. R., and J. J. Baneke. 2004. "Analyzing Psychopathology Items: A Case for Nonparametric Item Response Theory Modeling." Psychological Methods 9 (3): 354-368.

Morgan, K., J. Sproule, D. Weigand, and P. Carpenter. 2005. "A Computer-Based Observational Assessment of the Teaching Behaviours that Influence Motivational Climate in Physical Education." Physical Education \& Sport Pedagogy 10 (1): 83-105.

Ntoumanis, N. 2005. "A Prospective Study of Participation in Optional School Physical Education using a Self-Determination Theory Framework.” Journal of Educational Psychology 97 (3): 444-453.

Okely, A. D., M. L. Booth, and T. Chey. 2004. "Relationships between Body Composition and Fundamental Movement Skills among Children and Adolescents." Research Quarterly for Exercise and Sport 75 (3): 238-247.

Prochaska, J. J., J. F. Sallis, D. J. Slymen, and T. L. McKenzie. 2003. "A Longitudinal Study of Children's Enjoyment of Physical Education.” Pediatric Exercise Science 32: 963-975. 
Reeve, J. 2012. “A Self-Determination Theory Perspective on Student Engagement." In Handbook of Research on Student Engagement, edited by S. L. Christenson, A. L. Reschly, and C. Wylie, 149172. New York: Springer-Verlag.

Reeve, J., H. Jang, D. Carrell, S. Jeon, and J. Barch. 2004. "Enhancing Students' Engagement by Increasing Teachers' Autonomy Support." Motivation and Emotion 28 (2): 147-169.

Rose, A. J., and K. D. Rudolph. 2006. "A Review of Sex Differences in Peer Relationship Processes: Potential Trade-Offs for the Emotional and Behavioral Development of Girls and Boys." Psychological Bulletin 132 (1): 98-131.

Sarrazin, P. G., D. P. Tessier, L. G. Pelletier, D. O. Trouilloud, and J. P. Chanal. 2006. "The Effects of Teachers' Expectations about Students' Motivation on Teachers' Autonomy Supportive and Controlling Behaviors." International Journal of Sport and Exercise Psychology 4 (3): 283-301.

Scully, D., and J. Clarke. 1997. "Gender Issues in Sport Participation." In Young People's Involvement in Sport, edited by J. Kremer, K. Trew, and S. Ogle, 23-52. London: Routledge.

Sijtsma, K., P. Debets, and I. W. Molenaar. 1990. "Mokken Scale Analysis for Polychotomous Items: Theory, a Computer Program and an Empirical Application." Quality and Quantity 24 (2): 173-188.

Skinner, E. A., and A. J. Belmont. 1993. "Motivation in the Classroom: Reciprocal Effects of Teacher Behavior and Student Engagement Across the School Year." Journal of Educational Psychology 85 (4): $571-581$.

Slingerland, M., L. Haerens, G. Cardon, and L. Borghouts. 2014. "Differences in Perceived Competence and Physical Activity Levels during Single-Gender Modified Basketball Game Play in Middle School Physical Education." European Physical Education Review. 20 (1): 20-35.

Spessato, B. C., C. Gabbard, N. Valentini, and M. Rudisill. 2013. "Gender Differences in Brazilian Children's Fundamental Movement Skill Performance." Early Child Development and Care 183 (7): 916-923.

Standage, M., J. L. Duda, and N. Ntoumanis. 2003. "A Model of Contextual Motivation in Physical Education: Using Constructs from Self-Determination and Achievement Goal Theories to Predict Physical Activity Intentions." Journal of Educational Psychology 95 (1): 97-110.

Standage, M., J. L. Duda, and N. Ntoumanis. 2005. "A Test of Self-Determination Theory in School Physical Education.” Britisch Journal of Educational Psychology 75: 411-433.

Statistics Netherlands. 2011a. "Income, Education and Work: Percentage of People with High Incomes by District." CBS in uw buurt. Accessed October, 2013. http://www.cbsinuwbuurt.nl/ \#wijken2011 percentage personen met hoog inkomen.

Statistics Netherlands. 2011b. "Income, Education and Work: Percentage of People with Low Incomes by District." CBS in uw buurt. Accessed October, 2013. http://www.cbsinuwbuurt.nl/ \#wijken2011_percentage_personen_met_laag_inkomen.

Stichting Leerplanontwikkeling. 2006. "Kerndoelen primair onderwijs [Main objectives primary education]." Acccessed March, 2014. http://www.slo.nl/primair/kerndoelen/.

Stodden, D. F., J. D. Goodway, S. J. Langendorfer, M. A. Roberton, C. Garcia, and L. E. Garcia. 2008. "A Developmental Perspective on the Role of Motor Skill Competence in Physical Activity: An Emergent Relationship." Quest 60 (2): 290-306.

Terwee, C. B., S. D. M. Bot, M. R. de Boer, D. A. W. M. van der Windt, D. L. Knol, J. Dekker, L. M. Bouter, and H. C. W. de Vet. 2007. "Quality Criteria were Proposed for Measurement Properties of Health Status Questionnaires." Journal of Clinical Epidemiology 60 (1): 34-42.

Ulrich, D. A. 2000. Test of Gross Motor Development-2. 2nd ed. Examiner's Manual. Austin, TX: Prod-Ed.

Vallerand, R. J., M. S. Fortier, and F. Guay. 1997. "Self-Determination and Persistence in a Real-Life Setting: Toward a Motivational Model of High School Dropout." Journal of Personality and Social Psychology 72 (5): 1161-1176.

Van den Berghe, L., M. Vansteenkiste, G. Cardon, D. Kirk, and L. Haerens. 2014. "Research on SelfDetermination in Physical Education: Key Findings and Proposals for Future Research." Physical Education and Sport Pedagogy 19 (1): 97-121.

Vandorpe, B., J. Vandendriessche, J. Lefevre, J. Pion, R. Vaeyens, S. Matthys, R. Philippaerts, and M. Lenoir. 2010. "The korperkoordinationsTest Für Kinder: Reference Values and Suitability for 612-Year-Old Children in Flanders." Scandinavian Journal of Medicine \& Science in Sports 21 (3): $378-388$.

Vandorpe, B., J. Vandendriessche, R. Vaeyens, J. Pion, S. Matthys, J. Lefevre, R. Philippaerts, and M. Lenoir. 2012. "Relationship between Sports Participation and the Level of Motor Coordination in Childhood: A Longitudinal Approach." Journal of Science and Medicine in Sport 15 (3): 220-225. 
Van Weerden, J., F. Van der Schoot, and B. Hemker. 2008. Periodieke Peiling Van Het Onderwijsniveau. Balans Van Het Bewegingsonderwijs Aan Het Einde Van De Basisschool 3. Uitkomsten Van De Derde Peiling in 2006. Arnhem: Stichting Cito Instituut voor Toetsontwikkeling.

Vlachopoulos, S. P., and S. Michailidou. 2006. "Development and Initial Validation of a Measure of Autonomy, Competence, and Relatedness in Exercise: The Basic Psychological Needs in Exercise Scale." Measurement in Physical Education and Exercise Science 10 (3): 179-201.

Wilson, P. M., W. T. Rogers, W. M. Rodgers, and T. C. Wild. 2006. "The Psychological Need Satisfaction in Exercise Scale." Journal of Sport and Exercise Psychology 28 (3): 231-251.

Xiang, P., R. McBride, and J. Guan. 2004. "Children's Motivation in Elementary Physical Education: A Longitudinal Study.” Research Quarterly for Exercise and Sport 75 (1): 71-80.

\section{Appendix 1. Competence, Autonomy, classmate-Relatedness and teacher- Relatedness Scale}

I put effort in this PE-class because ...

\section{Competence}

(1) I feel I do very well

(2) I feel like I am capable of doing even the most challenging activities

(3) I feel I am able to perform the activities my PE-teacher asks of me

(4) I feel good about the way I am able to complete challenging activities

\section{Autonomy}

(1) We do activities which I also would choose myself

(2) I feel free to choose which activities I participate in

(3) I feel like I have a say in choosing the activities that we do

(4) I feel that I can choose how to participate (choice in how to perform the activity, with whom or how long).

\section{Classmate Relatedness}

(1) The relationships with my classmates are friendly

(2) I feel like my classmates and I understand each other

(3) I get along with my classmates

(4) I feel comfortable with my classmates

\section{Teacher Relatedness}

(1) I get along with my PE-teacher

(2) I feel comfortable with my PE-teacher

(3) I feel my PE-teacher gives everyone the same opportunities

(4) I feel attached to my PE-teacher because he/she accept me for who I am

(5) I feel like my PE-teacher and I understand each other

(6) The relationship with my PE-teacher is friendly 


\section{Appendix 2. Adapted Behavioral Regulations in Physical Education Questionnaire}

I put effort in this PE-class because ...

\section{Autonomous motivation}

(1) I value the benefits of this PE-class

(2) This PE-class is fun

(3) I enjoy this PE- class

(4) I find this PE-class personally meaningful

(5) I get pleasure from participating in this PE-class

(6) I find this PE-class a pleasurable activity

(7) I fully recognize the usefulness of this PE class

\section{Controlled motivation}

(1) Others will appreciate me less if I didn't

(2) It is the only way to please others

(3) I feel like a failure if I didn't

(4) I felt the pressure of others to participate in this PE-class

(5) It is the only way to be proud of myself

\section{Appendix 3. Overview of the items of three BOT-2 subtests}

\begin{tabular}{|c|c|c|}
\hline BOT-2 subscale & Items & $\begin{array}{l}\text { Max. Point } \\
\text { Scores }\end{array}$ \\
\hline \multirow{5}{*}{$\begin{array}{l}\text { Speed \& agility for the } \\
\text { measurement of } \\
\text { locomotor skills }\end{array}$} & Shuttle run & 12 \\
\hline & Stepping sideways over a balance beam & 10 \\
\hline & One legged stationary hop & 10 \\
\hline & One legged side hop & 10 \\
\hline & Two legged side hop & 10 \\
\hline \multirow{7}{*}{$\begin{array}{l}\text { Upper limb coordination } \\
\text { for the measurement of } \\
\text { object control skills }\end{array}$} & Dropping and catching a ball with both hands & 5 \\
\hline & Catching a tossed ball & 5 \\
\hline & Dropping and catching a ball with one hand & 5 \\
\hline & Catching a tossed ball with one hand & 5 \\
\hline & Dribbling a ball with one hand & 7 \\
\hline & Dribbling a ball with alternating hands & 7 \\
\hline & Throwing a ball to a target & 5 \\
\hline \multirow[t]{9}{*}{ Balance } & Standing with feet apart on a line with eyes open & 4 \\
\hline & Walking forward on a line & 4 \\
\hline & Standing on one leg on a line with eyes open & 4 \\
\hline & Standing with feet apart on a line with eyes closed & 4 \\
\hline & Walking forward heel-to-toe on a line & 4 \\
\hline & Standing on a one leg on a line with eyes closed & 4 \\
\hline & Standing on one leg on a balance beam with eyes open & 4 \\
\hline & Standing heel-to-toe on a balance beam & 4 \\
\hline & Standing on one leg on a balance beam with eyes closed & 5 \\
\hline
\end{tabular}

